\title{
Desmoplastic fibroma of the ulna
}

\author{
Sainath K Andola ${ }^{1}$, Saara Neeha ${ }^{2, *}$, Anita A Mahanta ${ }^{3}$ \\ ${ }^{1}$ Professor, ${ }^{2}$ Post Graduate, ${ }^{3}$ Associate Professor, Dept. of Pathology, Mahadevappa Rampure Medical College, Karnataka, India \\ *Corresponding Author: Saara Neeha \\ Email: drsaara.neha@gmail.com
}

\begin{abstract}
Introduction: Desmoplastic fibroma is an extremely rare, locally aggressive, benign bone tumour with incidence of $0.1 \%$ of primary bone tumors.

It is composed of spindle cells with minimal cytological atypia and abundant collagen.

Diagnosis is made on radiology and histopathology.

Case Summary: A $17 \mathrm{yr}$ female patient presented with pain and swelling in left forearm since 9yrs, slowly progressive in nature. Radiograph showed an osteolytic lesion of the proximal ulna. En-bloc excision was done. Grossly the tumor was $13 \times 6 \times 2.5 \mathrm{~cm}$, hard in consistency with grey-white mass on cut section. Microscopically it was composed of spindle shaped cells with elongated bland appearing nuclei arranged in whorled pattern and fascicles with abundant collagen present between spindle cells. No pleomorphism or mitoses were noted.

Conclusion: Desmpoplastic fibroma is a very rare locally aggressive benign neoplasm of bone. The diagnosis and management are often difficult and requires a combined speciality approach.
\end{abstract}

Keywords: Desmoplastic fibroma, Ulna, Bone tumor, Spindel cell, Collagen.

\section{Introduction}

Desmoplastic fibroma is an extremely rare, benign, well-differentiated, locally aggressive bone tumor with an incidence of $0.1 \%$ of all primary bone tumors and characterised by spindle cells with minimal cytological atypia and abundant collagen production. ${ }^{1} \mathrm{Jaffe}$ in 1958 , first described desmoplastic fibroma as a primarily osseous-arised aggressive fibromatosis of femur, tibia and scapula. ${ }^{2}$ Desmoplastic fibroma was considered to be the osseous counterpart of extra-abdominal desmoid tumour because of the infiltrative pattern of growth. ${ }^{3}$ It commonly involves the jaw, femur and tibia, although any bone may be involved. Involvement of the bones of forearm is an extremely rare occurence. ${ }^{4}$

Patients present with a variety of symptoms including pain, swelling, deformity or loss of function.

Plain radiographs reveal a trabeculated, lucent, expansile lesion often with lobulated margin. ${ }^{5}$

We report a case of desmoplastic fibroma of ulna involving proximal two thirds.

\section{Case Report}

A 17 years old female patient presented with complaints of progressively increasing swelling and pain in left forearm since 9 years.

On clinical examination there was tenderness and swelling in the upper part of the left forearm. (Fig. 1)

On plain radiograph, an expansile, osteolytic lesion with thinned out cortex involving proximal two-thirds of ulna was noted, lesion was located in the diaphysis, with extension to metaphysis \& epiphysis. No matrix was noted. (Fig. 2)

Excision of the tumor was performed and fibular graft was used to reconstruct elbow. Tenodesis of fibular head was done with triceps muscle.
Grossly, the tumor measured $13 \mathrm{~cm} \times 6 \mathrm{~cm} \times 2.5 \mathrm{~cm}$. Cut surface was homogenous, firm, grayish white in appearance, involving the entire bone with cortical thinning. (Fig. 3 a \& b)

On microscopic examination, the tumor composed of interlacing fascicles and whorls of spindle cells with an elongated and bland nuclei. Abundant collagen was present between the spindle cells. Areas of normal osteoid was also seen. No pleomorphism, no cytologic atypia and no mitoses. (Fig. 4 \& 5)

A diagnosis of desmoplastic fibroma was made based on the radiological and histopathological findings.

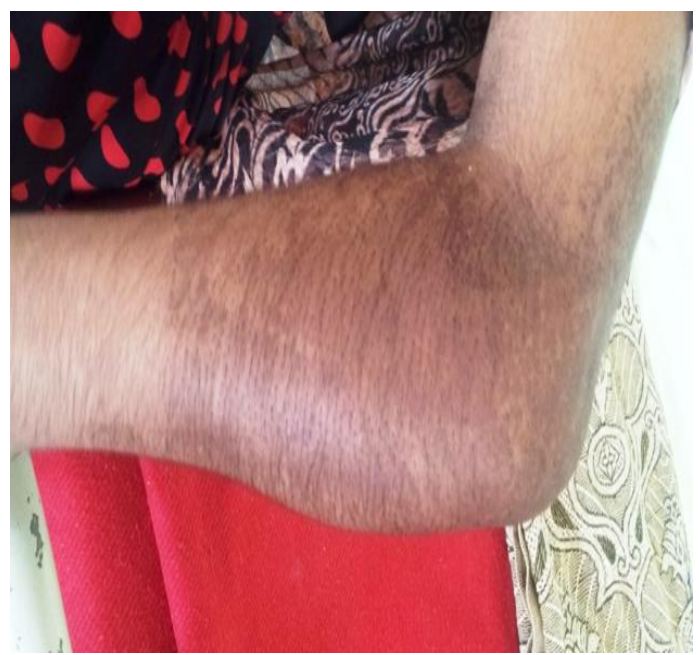

Fig. 1: Photograph showing swelling in left forearm 


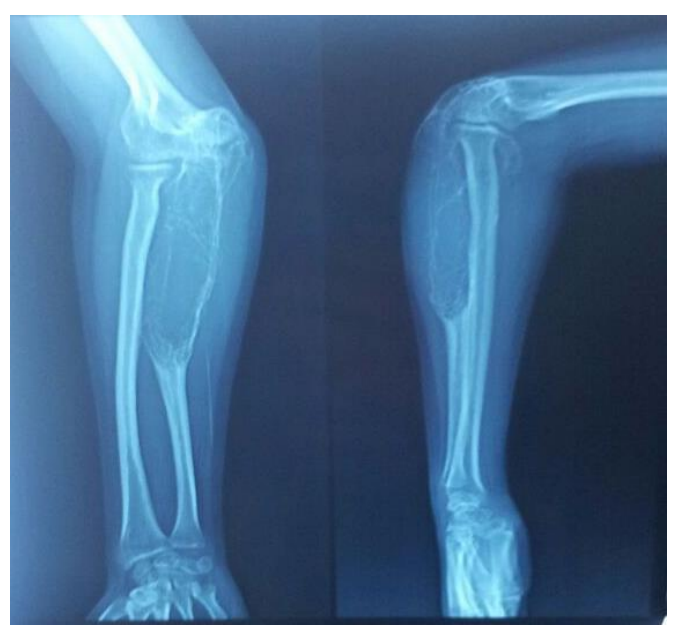

Fig. 2: X-ray showing lytic lesion in the proximal ulna involving the epiphysis
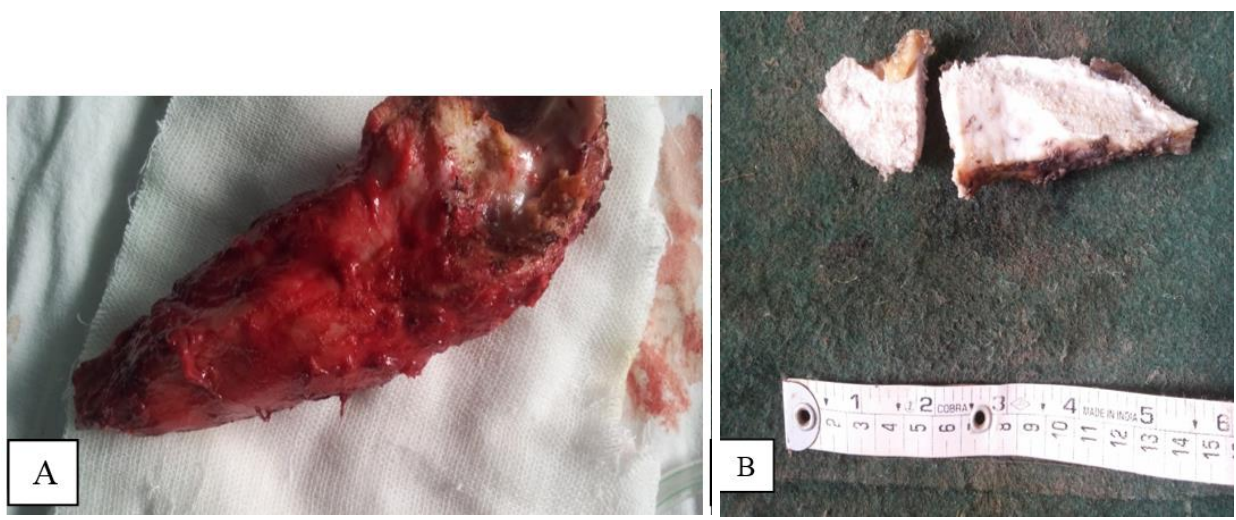

Fig. 3: (A) Surgical specimen of the excised tumor; (B): Cut section showing gray white tumor involving the entire bone
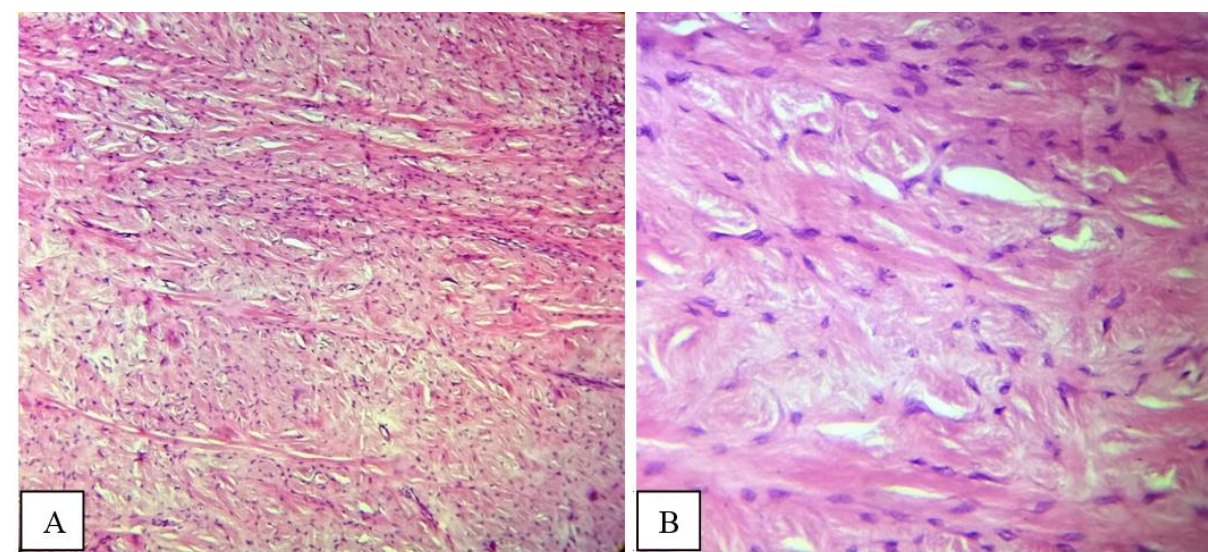

Figure 4: (A) Low magnification view showing fascicles of spindle shaped cells with dense collagen; (B): High magnification view showing bland spidle cells 

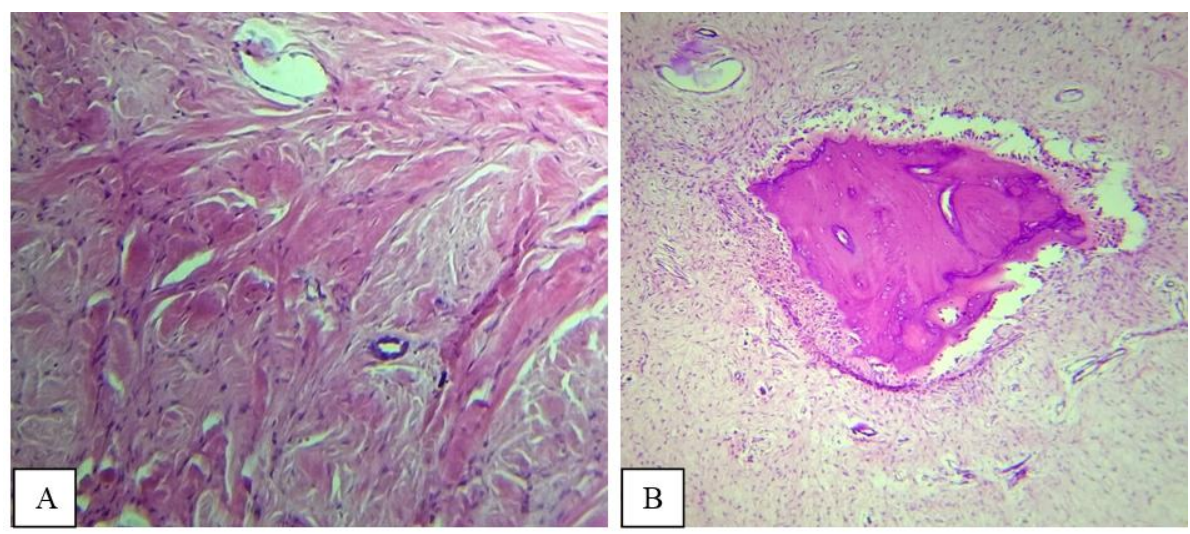

Figure 5: (A) High magnification view of thich collagen bundles with spindle cells in between them. (B): Low magnification view showing entrapment of normal bone in between the tumor cells

\section{Discussion}

WHO defines Desmoplastic fibroma as a rare, benign bone tumour composed of spindle cells with minimal cytological atypia and abundant collagen production. It is the intra-osseous counterpart of desmoid tumour, locally aggressive with high rate of recurrence.

The tumour usually affects people in their first to third decade of life with a peak at 15 years of age. ${ }^{6}$ It can be asymptomatic at the initial stages and later present with a variable symptoms including pain, swelling, deformity, effusion into the joint space or loss of function and pathological fractures. ${ }^{7,8}$ Desmoplastic fibroma can involve any bone but is most often found in the mandible (22\%), followed by the femur $(15 \%)$, pelvic bones (13\%), radius (12\%), and tibia (9\%). ${ }^{1,9}$

The etiological factors of desmoplastic fibroma are not known, although an association with trauma, endocrine factors, genetic aberrations, have been suggested. Mutations in $\beta$-catenin and APC genes have been implicated in the pathogenesis of desmoid-type fibromatosis. Genetic association with trisomy 8 and 20 have been demonstrated by Fluoroscent in situ hybridization (FISH) technique. ${ }^{10}$ This finding is similar to that seen in soft tissue desmoid tumor.

Radiological findings are non specific showing well defined multicystic, expansile, lytic lesions giving bubbly appearance. In the long bone, they are centered in the metaphysis, with occasional epiphyseal involvement. The cortex is often focally destroyed.

Most lesions have a low to intermediate signal on T2- weighted images in MRI. ${ }^{6}$

CT and MRI are helpful in assessing the extent of disease and margins. The diagnosis is very difficult on radiographical imaging alone as many tumours have similar radiological appearances. Hence biopsy is the gold standard method of determining the exact nature of the lesion as it provides a tissue diagnosis. ${ }^{11}$

Grossly, desmoplastic fibromas are firm with a gray white cut surface.

Microscopically the lesion is composed of spindle cells having bland, oval, or elongated nuclei (fibroblasts/ myofibroblasts) on a richly collagenous, variably hyalinized background. The degree of cellularity is variable but cellular atypia and pleomorphism are minimal or absent. Mitoses are rare. The tumor can show variable cellularity ranging from mild, moderate or high with or without bone involvement. ${ }^{10}$

Immunohistochemistry does not aid in the diagnosis as the lesions of desmoplastic fibroma are usually positive for vimentin, which is a nonspecific and non-diagnostic finding. No specific, reliable IHC marker(s) for labeling lesional cells in desmoplastic fibroma have been recognised; therefore, it remains a diagnosis of exclusion.

Differential diagnosis of desmoplastic fibroma include benign and malignant spindle cell tumors. Low grade fibrosarcoma is extremely difficult to distinguish, however fibrosarcomas will have cellular atypia, occasional mitotic figures, and a "herringbone" arrangement of cells. Fibrous dysplasia with woven bone and non ossifying fibroma can mimic desmoplastic fibroma, but distinction can be made based on the characteristic radiographic findings. Microscopically fibrous dysplasia storiform pattern of spindle cells admixed with multinucleated giant cells and foam cells and in case of fibrous dysplasia, searching for woven bone can help, also the nuclei in fibrous dysplasia are shorter and more compact-looking than the elongated, slender nuclei seen in desmoplastic fibroma.

Treatment for desmoplastic fibroma tumor is marginal or wide surgical excision. Aggressive curettage is also recommended in view of its high recurrence rate. ${ }^{8}$ Other treatment strategies include radiotherapy and pharmacological treatments if needed. In cases where resection cannot be done adjuvant radiotherapy helps in controlling recurrence. ${ }^{12}$ Free fibular grafts are used for reconstruction of the upper limb. $^{4}$ 


\section{Conclusion}

Desmoplastic fibroma is a very rare, benign, well differentiated spindle cell tumor. It is locally aggressive tumor and because of high recurrence rate it needs to be distinguished from other benign spindle cell lesion by clinical, radiological and histopathological correlation.

\section{References}

1. Fornasico V, Pritzker KPH, Bridge JA. Desmplastic fibroma of bone. In: Fletcher CDM, Unni KK, Merten SF, eds. The World Health Organization classification of tumours. Pathology and genetics of tumors of soft tissue and bone. Lyon: IARC Press, 2002:288.

2. Jaffe HL. Tumors and tumorous conditions of the bones and joints. Philadelphia, PA: Lea and Febiger, 1958:298303.

3. Mirra J.M. vol. 1. Lea and Febiger; Philadelphia: 1989. pp. 735-747. (Desmoid tumours of bone (desmoplastic fibroma or "aggressive fibromatosis"). Bone tumours: clinical, radiological and pathological Correlations).

4. Goyal T, Rastogi S, Tripathy SK. Desmoplastic fibroma of ulna: Excision and reconstruction of olecranon with a fibular graft. Indian J Orthop. 2013;47:207-10.

5. Beabout J.W. vol. 5. JB Lippincott Company; Philadelphia: 1988. pp. 1-11. (Malignant and borderline malignant fibrogenic tumours of bone. Radiology: diagnosis, imaging, intervention).

6. McCarthy E. Fibroblastic and Fibrohistiocytic tumors. In: Goldblum J.R (ed). BONE AND SOFT tissue pathology (a volume in the series foundations in diagnostic pathology). $1^{\text {st }}$ edition. Philadelphia: saunders Elsevier; 2010;358-60.

7. Böhm P, Kröber S, Greschniok A, Laniado M, Kaiserling E. Desmoplastic fibroma of the bone: A report of two patients, review of the literature, and therapeutic implications. Cancer. 1996;78:1011-23.

8. Eyesan SU, Kehinde TG, Adesina AS, Ayeni CS, Abdulkareem BF. Desmoplastic fibroma of the ulna bone. Nigerian Medical Journal. Journal of the Nigeria Medical Association. 2015;56(2):153-155.

9. Said-Al-Naief N, Fernandes R, Louis P, Bell W, Siegal GP. Desmoplastic fibroma of the jaw: a case report and review of literature. Oral Surg Oral Med Oral Pathol Oral Radiol Endod. 2006;101(1):82-94.

10. TR Woods, DM Cohen, MN Islam, Y Rawal, I Bhattacharyya (2015) Desmoplastic Fibroma of the Mandible: a series of three cases and review of literature. Head Neck Pathol. 9(2):196-204.

11. Evans S, Ramasamy A, Jeys L, Grimer R. Desmoplastic fibroma of bone: A rare bone tumour. Journal of Bone Oncology. 2014;3(3-4):77-79.

12. M Schneider, AC Zimmermann, RA Depprich, NR Kübler, R Engers. Desmoplastic fibroma of the mandible - review of the literature presentation of a rare case. Head Face Med. 2009;5:25.

How to cite this article: Andola SK, Neeha S, Mahanta AA. Desmoplastic fibroma of the ulna. Indian J Orthop Surg. 2018;4(3):306-309. 